\title{
Comparative Study of Type-1 and Type-2 Fuzzy System in Decision Support System
}

\author{
Humaira, Yance Sonatha, Cipto Prabowo, Hidra Amnur, Rita Afyenni \\ Department of Information Technology, Politeknik Negeri Padang, Padang, Indonesia
}

\begin{tabular}{ll}
\hline \hline Article Info & ABSTRACT \\
\cline { 2 - 3 } Article history: & $\begin{array}{l}\text { This study compares between the Type-1 Fuzzy and Interval Type-2 Fuzzy in } \\
\text { Decision Support System (DSS). The case studied in this paper deals with } \\
\text { Received Jul 20, 2018 } \\
\text { Revised Jul 31, 2018 } \\
\text { Accepted Aug 5, 2018 }\end{array}$ \\
$\begin{array}{l}\text { recommend a decision in providing assessment criteria for the supplier. Both } \\
\text { of the systems used similar membership functions and rules. It is shown that } \\
\text { Type-2 Fuzzy can manage the level of uncertainty in decision making. In } \\
\text { Keyword: }\end{array}$ & $\begin{array}{l}\text { general, both systems have a surface resemblance. The result indicates that } \\
\text { Type-2 Fuzzy based on decision making with a level of uncertainty can } \\
\text { provide alternative decisions although it took about 56 times longer than } \\
\text { type-1. }\end{array}$ \\
DSS &
\end{tabular}

Copyright $\odot 2018$ Institute of Advanced Engineering and Science. All rights reserved.

\section{Corresponding Author:}

Humaira,

Department of Information Technology,

Politeknik Negeri Padang,

Padang, Indonesia.

Email: mira.humaira@gmail.com

\section{INTRODUCTION}

Many of Decision Support System (DSS) cases implement useful intelligence to increase the system performance, one of them is in designating the supplier. The company has fundamental reason appointing this supplier, some of them are 1) The company can put their concern on the main business while non main business can be delegated to the third party [1]. 2) To optimize the company predominance, 3) To exploit the supplier capability in increasing the product quality through the use of technology so the required time in expanding the new product becoming faster [2].

Generally, the supplier designation considers budget, delivery time, and quality. On the other hand, this supplier designation in advancing the new product has more complex criteria as well. Some of the criteria are reviewing the supplier characteristic, assessing the supplier company performance, and considering project characteristic related to the supplier offer [2]. From the above criteria can be found many information uncertainties and vaguenesses, taken as the example are market demand, used technology level or economic situation. Bearing in mind, linguistics determination of 'Low,' 'Medium,' 'High' for a variable enables everyone to have a different perception. Likewise, the obtained consequence of some experts is not agreeable to some others. Therefore, to minimize these uncertainty effects can be solvable using Fuzzy Type2 approach.

This paper investigates Type-1 (T1 FL) and Type-2 Fuzzy Logic (T2 FL), as the model for decisionmaking system. As time goes by, Prof. Zadeh realizes that T1 FL membership function is crisp as well. Then in 1975, Prof. Zadeh discovered T2 FL. However, T2 FL became popular in the early year of 2000. According to Mendel, T2 FL is utilized to model and minimize the uncertainty impacts that may occur on fuzzy logic. There are three types of uncertainties occurred, they are 1) a word used as antecedent and a rule consequent which can have different meanings to different people, 2) consequents obtained from the group of 
experts polling will often differ on the same rules because not all the experts will have same agreement on the rules, 3) noise found on T2 FL data can overcome this uncertainty by using the fuzzy T2 FL membership function [2]-[4]. Commonly used T2 FL is Interval T2 FL (IT2 FL).

T2 FL is able to model the uncertainty of intra-personal and inter-personal. According to Mendel [4], intra-personal uncertainty describes the uncertainty a person has about the word. Meanwhile, interpersonal uncertainty describes the uncertainty that a group of people has about the word, i.e. 'words mean different things to different people.' Words are used as antecedent and rule consequent. Antecedent or consequent uncertainties translate into uncertain antecedent or consequent membership functions. According to Turhan and Gariballdi, IT2 FL implementation on DSS allows it in capturing human decisions variations. Meanwhile, decision variations by fuzzy logic can be set using the uncertainty level in its membership function [5]. However, mostly IT2 FL is using on controlling and biomedical field. The use of IT2 FL in the DSS is still rare and is possibly developed. Then, this paper continues to compare between T1 FL and T2 FL and verify the uncertainty impact.

\section{THEORY}

\subsection{Type-1 Fuzzy Logic (T1 FL) and Type-2 Fuzzy Logic (T2 FL)}

T1 FL theory was first introduced by Zadeh in 1965 [5]. Mechanism of fuzzy logic consists of fuzzification, inference, and defuzzification [6]-[7]. Type-2 fuzzy sets (T2 FSs) concept, originally is also introduced by Zadeh as an extension of an ordinary fuzzy set concept, for instance, Type-1 fuzzy set [8].T2 FSs have grades of membership that are fuzzy themselves. They can be instrumental when such systems are taken in the situations by lots of uncertainties. The resulting Type-2 fuzzy logic systems (T2 FLS) have the potential to provide better performance than a Type-1 (T1) FLS. To date, due to the computational complexity of using a general T2 FS, most people only use interval T2 FSs in a T2 FLS, the result being an interval T2 FLS (IT2 FLS). The computations associated with interval T2 FSs are very manageable, which make an IT2 FLS quite practical [8].

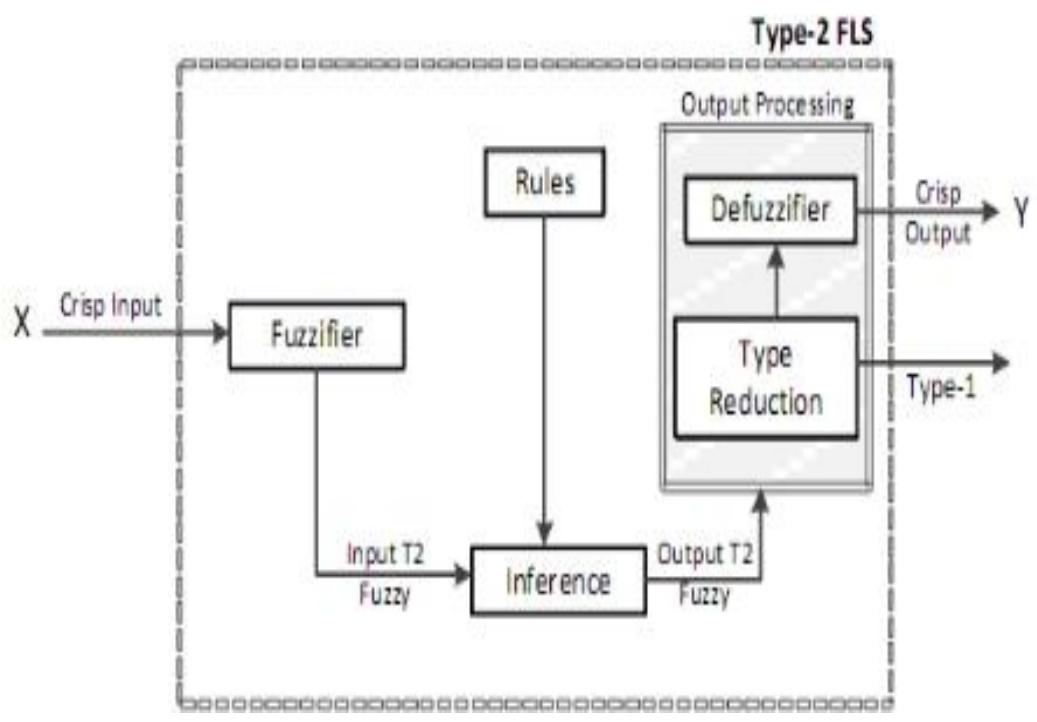

Figure 1. Type-2 FLS [8]

A general T2 FLS is depicted in Figure 1 and is very similar to the T1 FLS. The output processing block replaces the significant structural difference being on a T1 FLS defuzzifier block in a T2 FLS. That block consists of type-reduction followed by defuzzification [9]. Type-reduction maps a T2 FS into a T1 FS, and then de-fuzzification, as usual, maps T1 FS into a crisp number [8]. The first step in this chain of computations is to compute a firing interval. For the minimum t-norm, this calculation requires computing the sup-min operation between the lower (upper) MFs of the FOUs of each input and its corresponding antecedent. The firing interval propagates the uncertainties from all of the inputs through their respective antecedents. An example of computing the firing interval is depicted in the left-hand part of Figure 2 for a rule that has two antecedents [10]-[12]. 


\subsection{Decision Support System (DSS)}

Also, a decision refers to a choice made between two or more alternatives. Every day, all of us are making decisions. However, most major organizational decisions are made by managers [13]. According to Gorry and Scott Morton (1971) define DSS as Interactive Computer-Based Systems, which help decision makers utilizing data and models to solve unstructured problems. Another classic definition of DSS, provided by Keen and Scott Morton (1978) revealed that decision refers to support system couples of the intellectual resources of individuals with the capabilities of the computer to improve the decisions quality. It is a computer-based support system to manage the decision-makers in dealing with semi-structured problems. The early definition of a DSS identifies it as a system intended to support managerial decision makers in semi-structured situations. At this time, DSS was meant to be an adjunct to decision-makers to extend their capabilities but not to replace their judgment.

\subsection{A DSS Application}

A DSS is usually built to support the solution of a particular problem or to evaluate an opportunity such it is called a DSS application. A DSS is an approach (or methodology) for supporting decision-making. It uses an interactive, flexible, adaptable CBIS is specially developed for supporting the solution to a specific non-structured management problem. It uses data, provides a natural user interface, and can incorporate the decision-makers insight [13]. Also, a DSS usually uses models and is built (often by end-users) by an interactive and iterative process. It supports all decision-making phases and may include a knowledge component. Finally, a DSS can be used by a single user on a PC or can be Web-based to be used by many people at several locations [13].

Many companies are turning to DSSs to improve their decision making. Reasons cited by managers for the increasing use of DSSs are new and accurate information is needed, information is needed fast, and tracking the company's numerous business operations is increasingly difficult. Conversely, the company is operating in an unstable economy; it faces increasing foreign and domestic competition; the company's existing computer system does not correctly support the objectives of increasing efficiency, profitability, and entry into profitable markets.

\section{METHODOLOGY}

Case selection of suppliers to develop new products refers to a study by Carrera and Mayorga [2]. This research discusses the selection of suppliers to develop new products using the approach method fuzzy type 1. It generates criteria and rules. There are ten criteria as input to the system, namely the level of technology, economic situation, production capacity, market share, level of quality, cost reduction, delivery rate, part quotation, investment cost and project time. These criteria and rules are used in the fuzzy type-2 method.

The system is designed using a Context Diagram. This diagram shows a global and straightforward system as viewed in Figure 2.

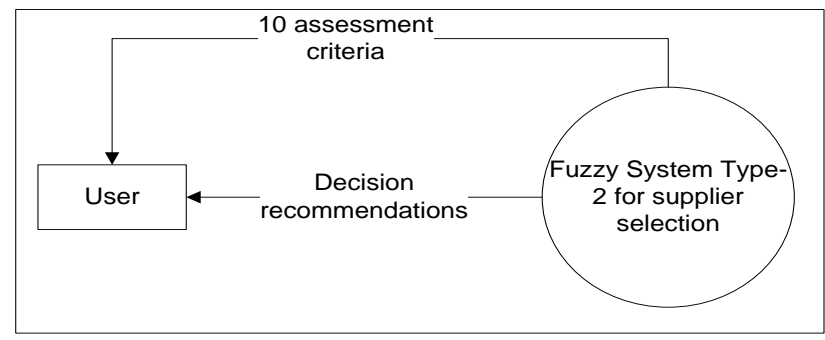

Figure 2. Context diagram of decision support system

These ten criteria are going to be input for the system. The decision support system to choose the supplier in developing a new product using Fuzzy Type-2 is a modular system. Here, modular means calculation completion of many criteria divided into several groups as seen in Figure 3. The settlement of modularly supplier selection case will generate an intermediate decision. The decision on this level can observe each represented group characteristic [2]. Likely, the experts take this modular approach to make the decision analysis easier. Thus, those ten criteria are arranged into three groups, consists of supplier characteristic, supplier performance, and project characteristic. 


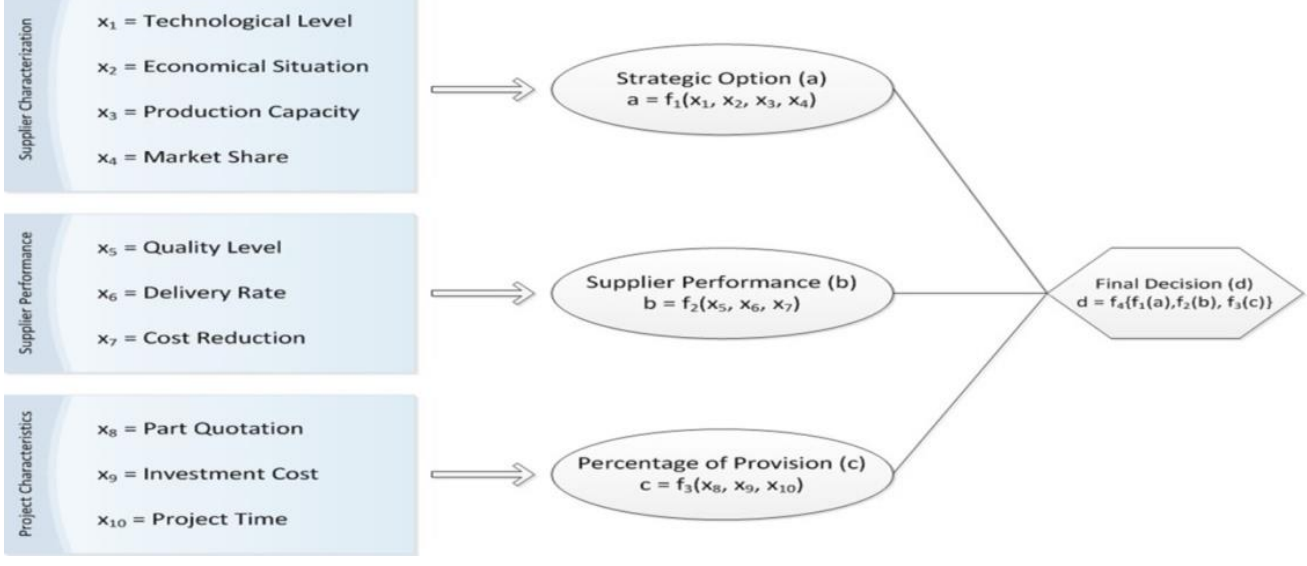

Figure 3. Criteria grouping in supplier selection to develop new product

Consequently in each group is going to perceive intermediate variable decision result $\{\mathrm{f}(\mathrm{a}), \mathrm{f}(\mathrm{b})$, $\mathrm{f}(\mathrm{c})\}$. Hence, the decision support system design using this Fuzzy Type-2 is divided into two Fuzzy Inference System (FIS) processes. The first FIS, the group (a), (b) and (c), is performed simultaneously. The second one, the output of each module is inserted into a group $(\mathrm{d})$. The detail system design can be seen from Figure 4 to Figure 8.

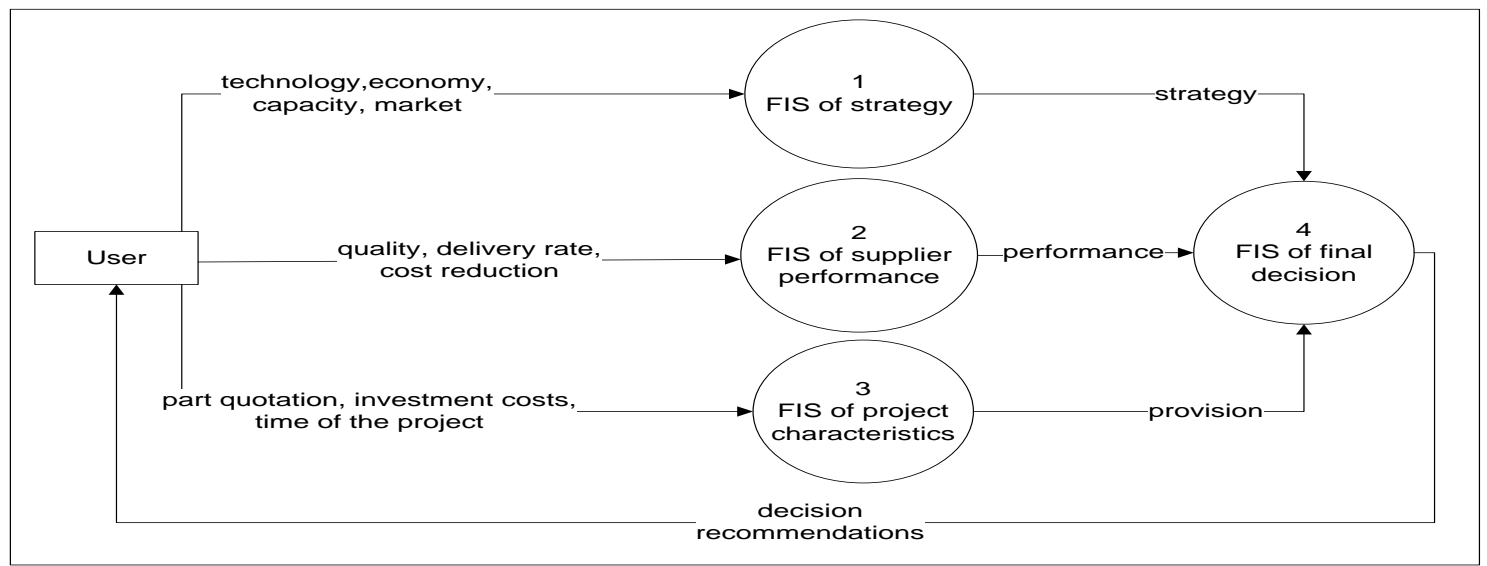

Figure 4. DFD Level 1

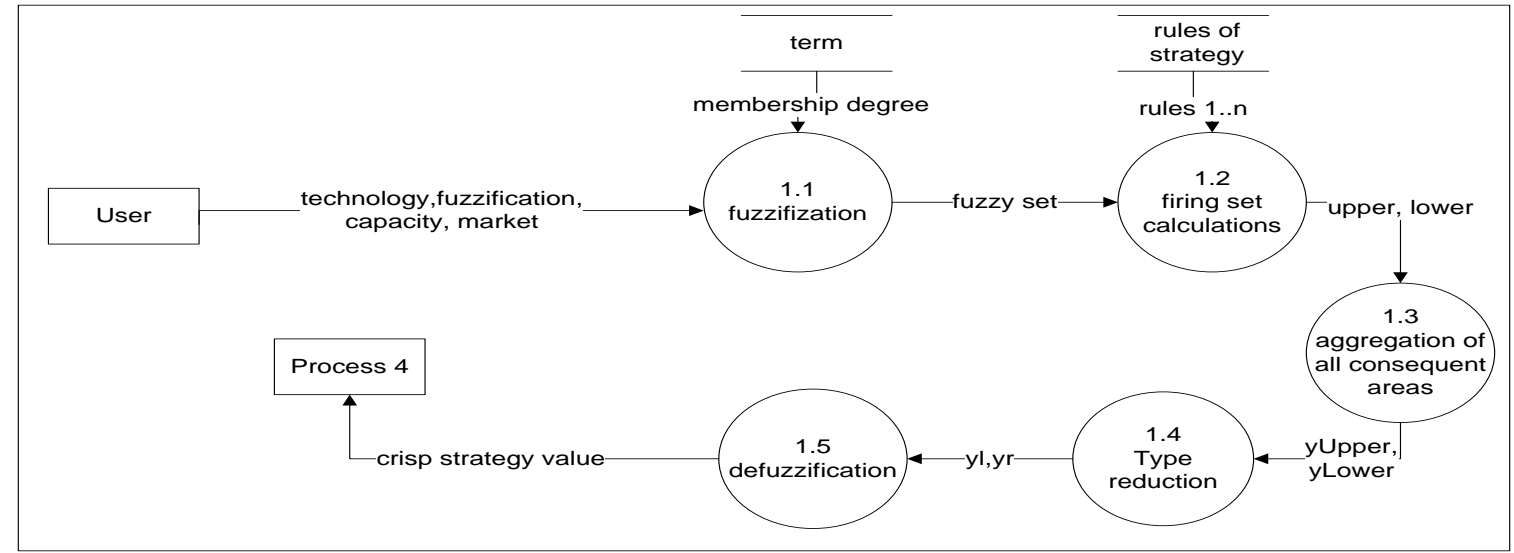

Figure 5. DFD Level 2 Process 1 the Fuzzy Inference for strategy 


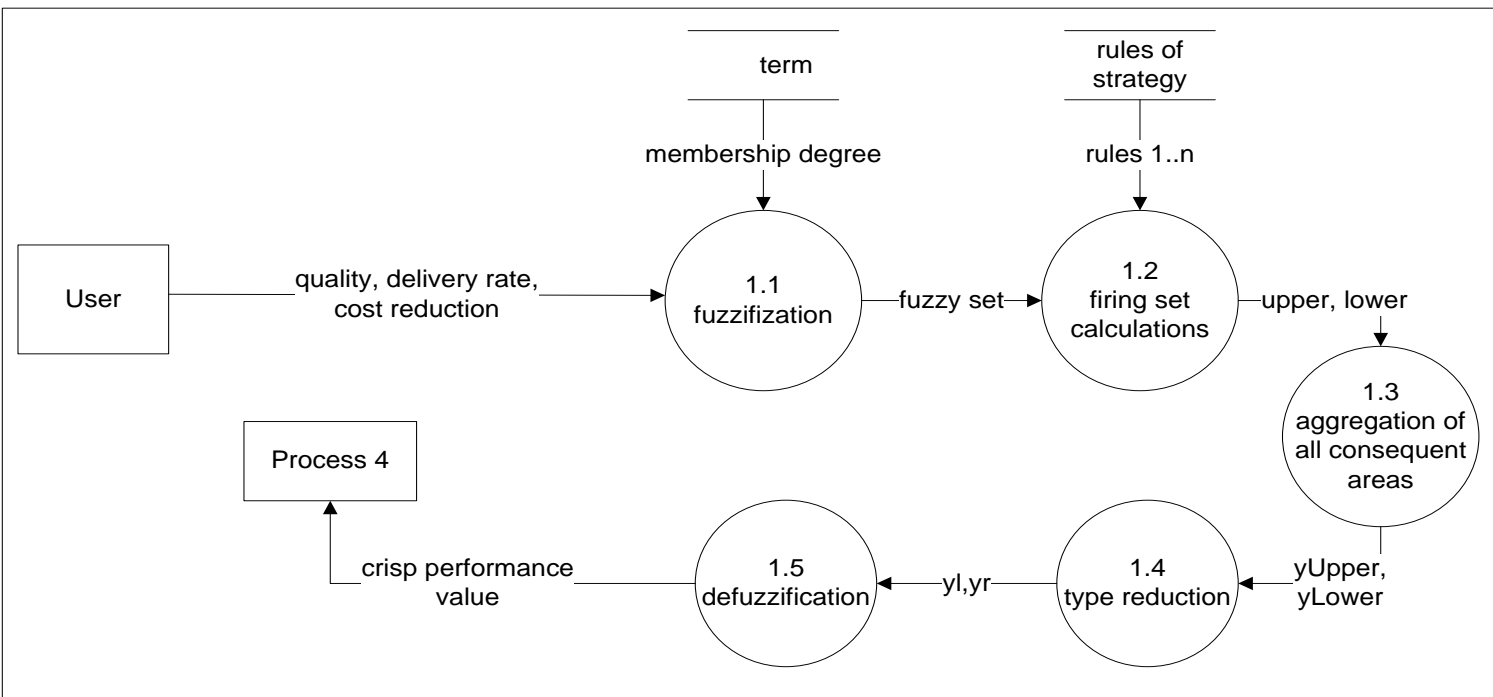

Figure 6. DFD Level 2 Process 2 Fuzzy Inference for supplier performance

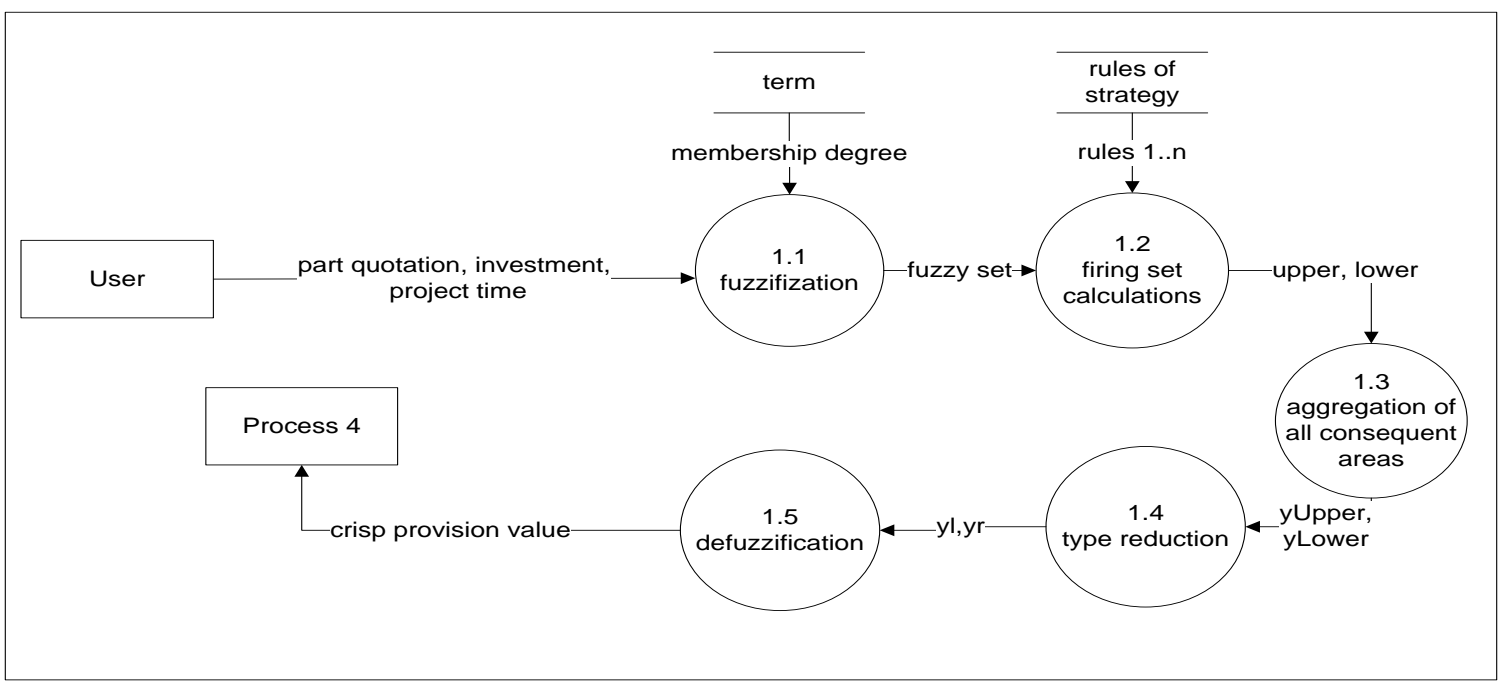

Figure 7. DFD Level 2 Process 3 Fuzzy Inference for provision percentage

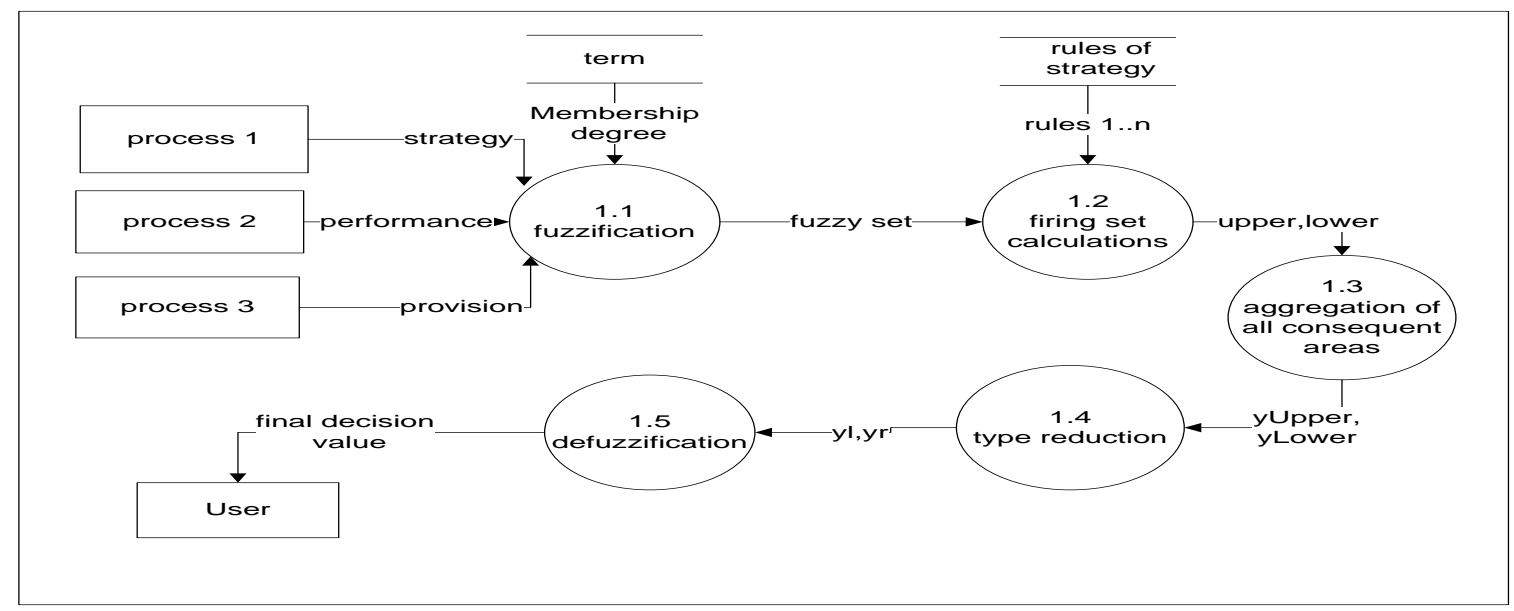

Figure 8. DFD Level 2 Process 4 Fuzzy Interference for obtaining a final decision 
In type-1 fuzzy uses Gaussian dan Generalized bell membership function in Table 1 can be seen rule base for the recommendation decision.

Table 1. Rule Base for Final Decision

\begin{tabular}{|c|c|c|c|c|}
\hline \multirow[b]{2}{*}{ No } & \multicolumn{3}{|c|}{ if } & \multirow{2}{*}{$\begin{array}{c}\text { Then } \\
\text { Final Decision }\end{array}$} \\
\hline & Strategic Option & $\begin{array}{c}\text { Supplier } \\
\text { Performance }\end{array}$ & $\begin{array}{l}\text { Percent of } \\
\text { Provision }\end{array}$ & \\
\hline 1 & Not Recommended & Critical & $0-10$ & Not Selected \\
\hline 2 & To Develop & Under Control & $10-30$ & Not Selected \\
\hline 3 & Not Recommended & Critical & $80-100$ & Not Selected \\
\hline 4 & To Develop & Reliable & $30-60$ & Second Choice \\
\hline 5 & To Develop & Under Control & $80-100$ & Second Choice \\
\hline 6 & Convenient & Under Control & $60-80$ & Second Choice \\
\hline 7 & To Develop & Autonomous & $80-100$ & Under Consideration \\
\hline 8 & Convenient & Reliable & $30-60$ & Under Consideration \\
\hline 9 & Convenient & Under Control & $60-80$ & Under Consideration \\
\hline 10 & Recommended & Autonomous & $60-80$ & Selected \\
\hline 11 & Recommended & Autonomous & $80-100$ & Selected \\
\hline
\end{tabular}

Both systems develop the same rules. In type-2 fuzzy system uses interval membership function. It has upper and lower membership function. Implementation of the Interval type-2 is relatively easier to manage than the other type-2 fuzzy. The interval type-2 fuzzy of membership functions define Gaussian and Generalized Bell with a midpoint that is uncertainty. This curve is used to form a fuzzy set [14]. Before the output established, type reduction and defuzzification will be processed first. Type of reduction is the reduction of type-2 to type-1. It uses the centroid (center of sums) method. Besides, this type of reduction process uses the EIASC algorithm [9],[15].

\section{RESULT AND ANALYSIS}

Consequent obtained by a group of experts polling is often different for the same rule because the experts would unnecessarily agree. However, it can be seen from Table 2 that the recommended decision has different decisions although crisp input is the same. The base interval can be affected by resolve decision. Type-1 fuzzy can do this with the additional rule. Variation decision IT2 FLS generated by this study previously confirms [3] that the variation in decision making using the Type-2 Fuzzy logic can be controlled by the level of uncertainty contained in membership functions.

Table 2. Crisp Output From Type-1 and Type-2

\begin{tabular}{ccccc}
\hline Group & Type-1 & $\begin{array}{c}\text { Type-2 } \\
\text { (interval 5) }\end{array}$ & $\begin{array}{c}\text { Type-2 } \\
\text { (interval 10) }\end{array}$ & $\begin{array}{c}\text { Type-2 } \\
\text { (interval 15) }\end{array}$ \\
\hline Strategic Option & 93,41 & 93,00 & 92,42 & 91,29 \\
Supplier Performance & 94,95 & 94,49 & 94,00 & 93,07 \\
Percentage of Provision & 86,86 & 86,22 & 85,60 & 84,80 \\
Output Final & 91,89 & 90,24 & 86,28 & 76,42 \\
Recommended Decision & Selected & Selected & Selected & Under Consideration \\
\hline
\end{tabular}

Type- 2 fuzzy took about 56 times longer than type- 1 fuzzy. The difference occurred this time is not a problem because the required processing time is in seconds. It can be seen in Table 3. One of the outstanding characteristics of the DSS is a relatively short time to get a decision. Intervals as input parameters for the membership function affect the shape of membership function itself. The greater interval is given forms increasing FOU area. The interval value is a wide range UMF with LMF. The distance here is implemented by calculating the difference between the two middle values. A form of membership functions is based on interval. Meanwhile, the surface for different intervals is changed a little. In nature, significant changes cannot be seen. However, if the note comes with detail, the changes are visible on their tops. Based on previous studies [4] confirming that changes in the surface make the IT2 FLS is more adaptive and can be understood as the relationship between inputs and outputs are complex and cannot be done by a T1 FLS. Also, the Karnik-Mendel state that the IT2 FLS can be viewed as a collection of different embedded T1 FLS. 
Table 3. Time Comparison Between Type-1 Fuzzy and Type-2 Fuzzy

\begin{tabular}{cc}
\hline Fuzzy System & Time (in a second) \\
\hline Type-1 & 0.047 \\
Type- 2 & 2.68 \\
\hline
\end{tabular}

The adaptive here is the one embedded T1 FL on IT2 FLS and used for interval limit computing of type reduction as changing the input. This adaptive is directly correlated with crisp output in Table 2 . Every tested data gets their crisp output which tends to descend with expanding interval. However, the exception is made on the first tested data as the crisp output is increasing.

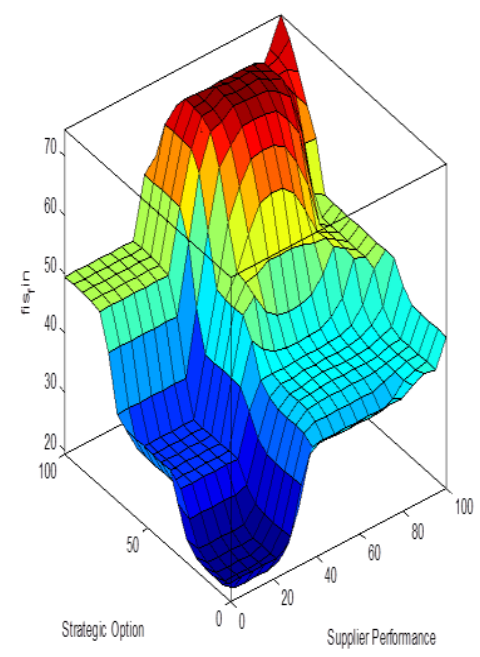

Interval by 5

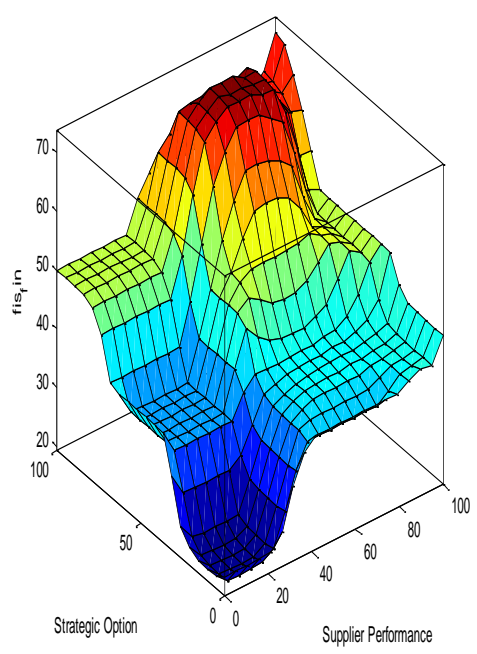

Interval by 10

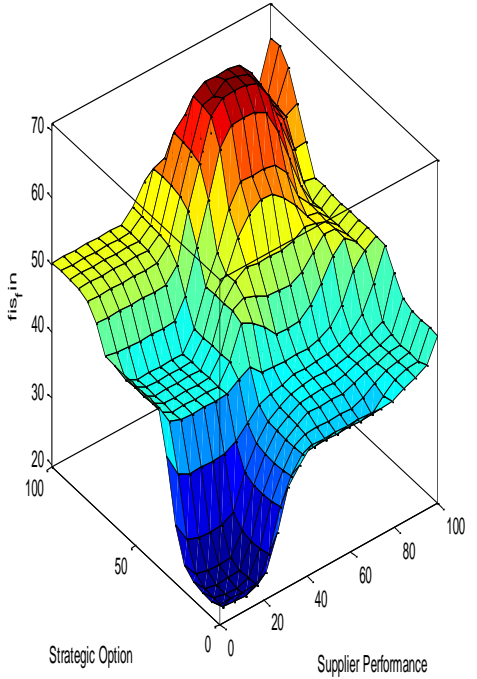

Interval by 15

Figure 9. I/O surface is adaptive toward interval changing

In general, formed landscape graphic between T1 FL and T2 FL have nature which tends to be similar. Figure 10(a-e) shows the same input for IT2 FL and T1 FL provides a different output value. Crisp output of T2 FL with interval 5 approaches the crisp output of T1 FL due to this interval 5 is the smallest interval of all.

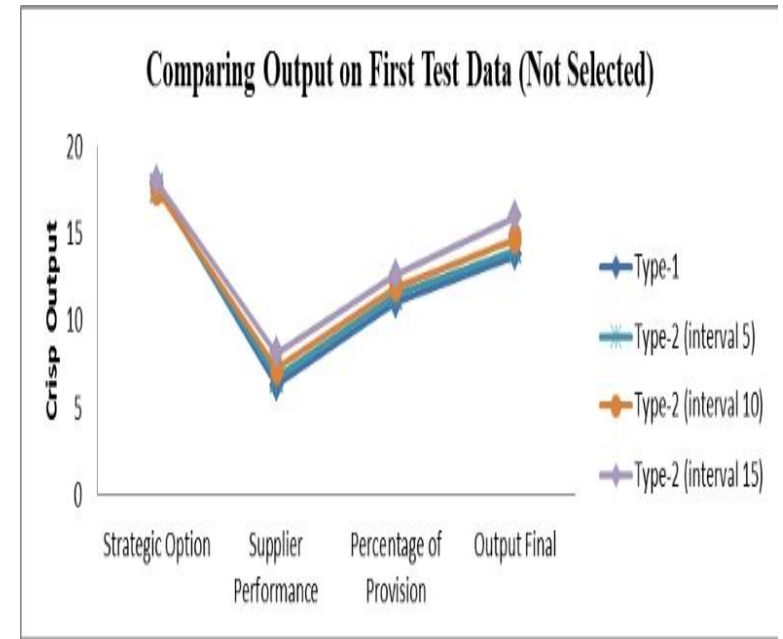

(a)

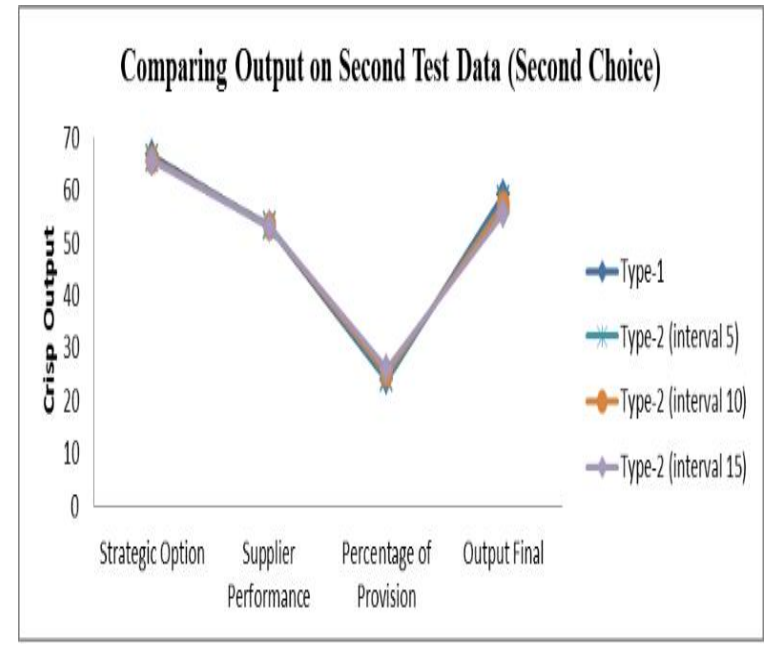

(b)

Comparative Study of Type-1 and Type-2 Fuzzy System in Decision Support System (Humaira) 


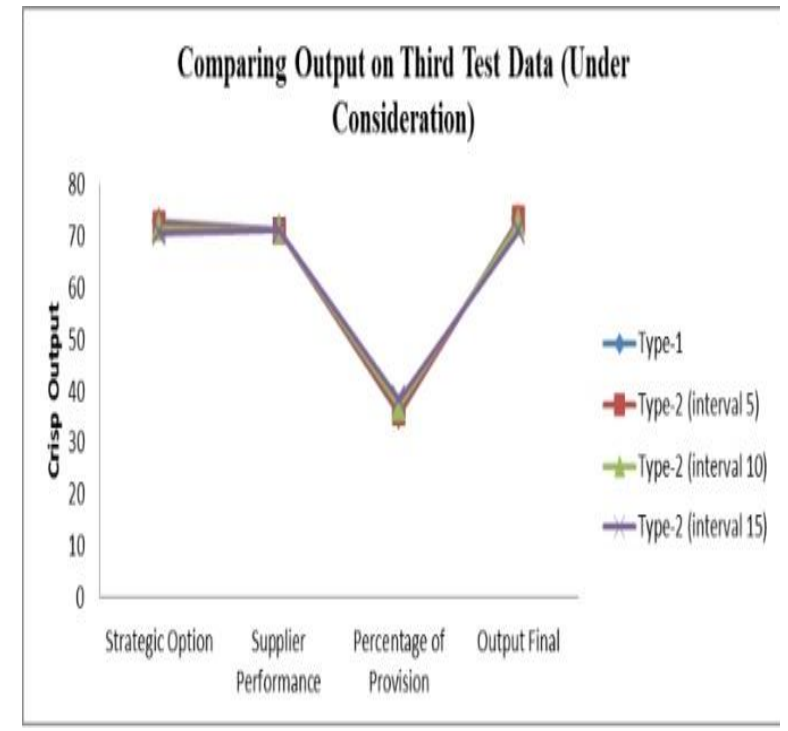

(c)

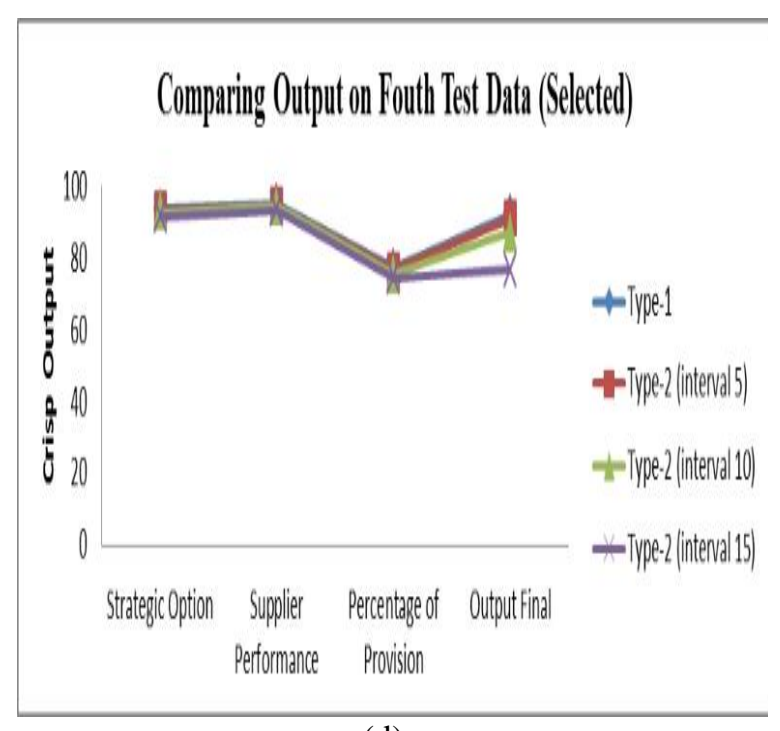

(d)

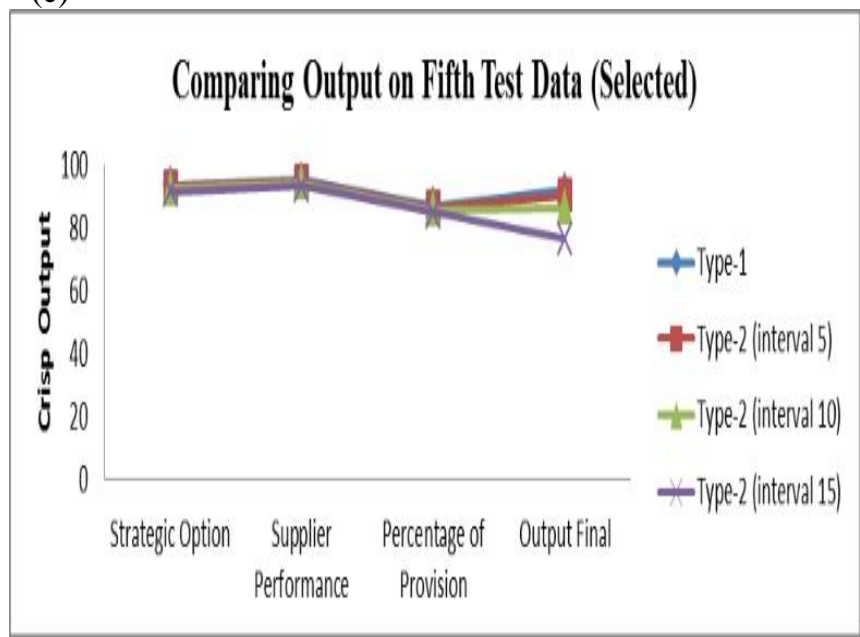

(e)

Figure 10. Comparing output on test data

Nevertheless, the final result is a bit varied between T1 FL and T2 FL; the recommended decision is still the same. Simulation of fifth data on interval 15 gives a different recommended decision with the interval 10 and 5. It can be seen in Table 2. T1, T2 (interval 5), T2 (interval 10) releases "Selected" as the recommended decision, whereas T2 (interval 15) has "under consideration" as its recommended decision. The difference on this recommended decision is referred to the uncertainty level. The larger the uncertainty level is, the more variation in decision results.

\subsection{Uncertainty Identification in Fuzzy Type-2}

\subsubsection{The Uncertainty of Each Person Linguistics Measurement}

Type-2 Fuzzy can model the uncertainty of intra-personal and inter-personal. According to Mendel [10], intra-personal uncertainty describes the uncertainty a person has about the word. While inter-personal uncertainty describes the uncertainty that a group of people has about the word, i.e., "words mean different things to different people." Words use as antecedent and consequent of the rule. Antecedent or consequent uncertainties translate into uncertain antecedent or consequent membership functions.

Figure 11 is one example of the interval membership functions shape on an input variable, namely Delivery Rate. For example, the membership of the number 50 is $[0.78,1]$. Observe that an IT2 FLS is bounded from the above and below by two T1 FLS, which are called Upper MF and Lower MF, respectively. Based on this, type-2 fuzzy Interval membership functions can be modeling the diverse opinions from different individuals. 


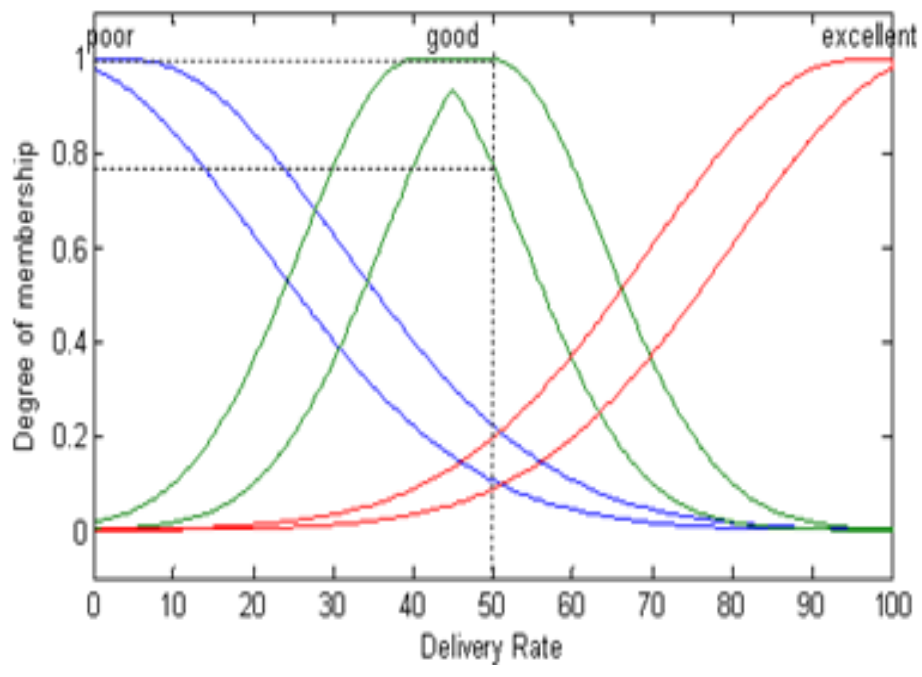

Figure 11. Gaussian MFs have uncertainty intervals associated with them

\subsubsection{Uncertainty on Group of People Toward A Rule}

Besides the different perception of each person on linguistics measurement, other uncertainties can be found on a group of people who have not agreed upon a particular rule.

From the result of several data simulation, especially the fourth data presents a decision recommendation variation, which is 'Selected' and 'Under Consideration.' Referred to the knowledge base in Table 1, the fourth data activates the 10th rule which has 'Selected' consequence. Figure 12 is system output with interval 15 input. Illustrated in the figure that the tenth and the eight rules are active. The output area is computed its crisp value using Centroid Type Reduction and afterward is defuzzified until reaching the number of 76.53. This number recommends 'Under Construction' decision. It is inappropriate with the tenth rule as it should set the 'Selected' decision. It is probably can be done by Fuzzy Type-1 System with the consequence of adding one more rule. This rule has similar antecedent with the tenth rule. However, its consequence is replaced by 'Under Consideration' decision. Nonetheless, in IT2 FLS System, this kind of decision variation can occur without changing the existed rule. In other words, IT2 FLS covers multiple input and output so that T1 FLS cannot perform this action taking the similar rule base.
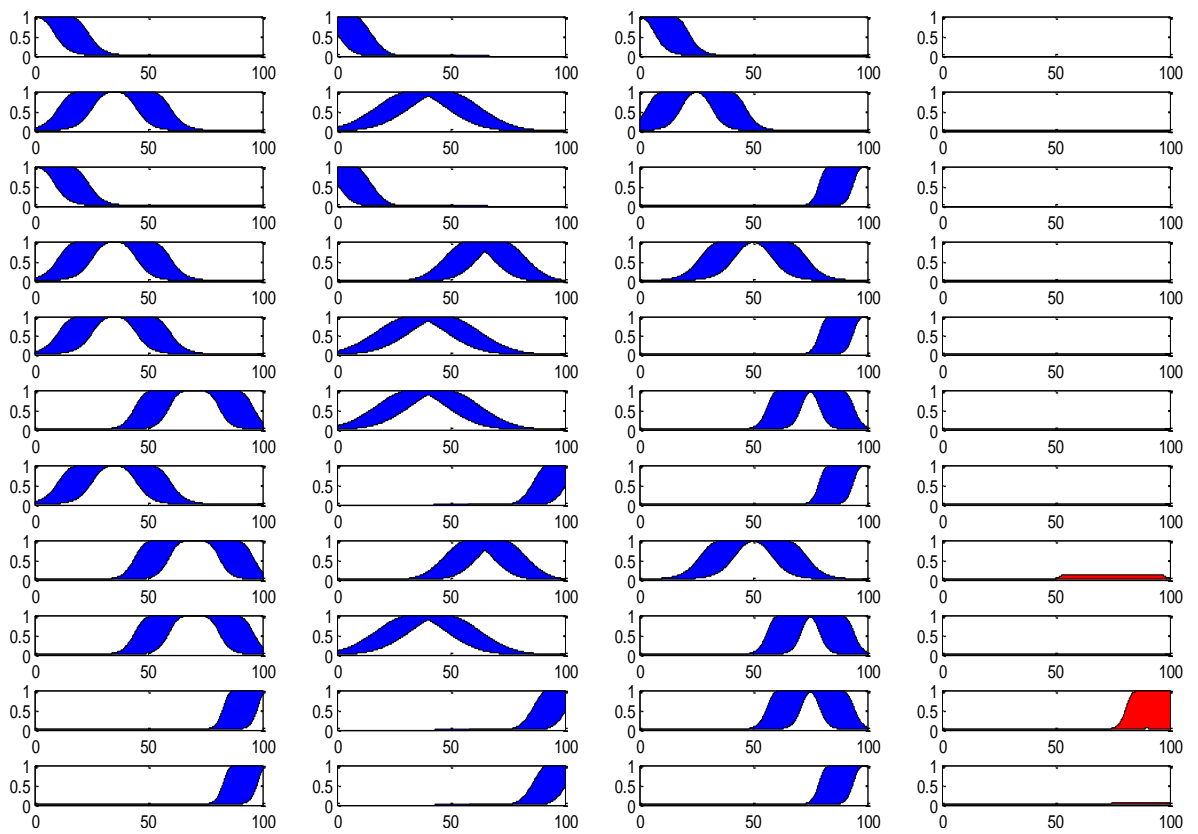

Figure 12. Rule plotting on the final group at interval 15 


\section{CONCLUSION}

T1 FLS used more rules than IT2 FLS likewise it could not implement complex input and output. Type-2 Fuzzy Systems can provide a variety of decisions based on the uncertainty level. This variation is one of the alternatives that will be considered by the decision-maker. There was different timing between T1 FLS and IT2 FLS. IT2 FLS took a long time getting the result compare than T1 FLS. Timing is a parameter in decision making. However, it is not a problem because the processing time is still under the tolerance limit. Further research can combine Fuzzy Type-2 System with Neural Network to attain better performance system.

\section{ACKNOWLEDGMENT}

A sincerely thankful to Prof. Bambang Riyanto for his constructive critics and advice in completing this research.

\section{REFERENCES}

[1] Vijay R Kannan and Keah Choon Tan, "Supplier Selection and Assessment: Their Impact on Business Performance," Supply Chain Management, vol. 38, no. 4, pp. 11-21, Nov 2002.

[2] Diego A Carrera and Rene V Mayorga, "Supply Chain Management: a Modular Fuzzy Inference System approach in Supplier Selection for New Product Development," Springer, vol. 19, pp. 1-12, July 2007.

[3] Turhan Ozen and Jonathan M. Garibaldi, "Effect of Type-2 Fuzzy Membership Function Shape on Modelling Variation in Human Decision Making".

[4] Dongrui Wu, "On the Fundamental Differences between Interval Type-2 and Type-1 Fuzzy Logic Controllers," IEEE Transactions on Fuzzy Systems, pp. 1-17, 2011.

[5] J.S.R Jang, C.T Sun, and E Mizutani, Neuro-fuzzy and Soft computing. US: Prentice Hall, 1997.

[6] Agis Baswara Agus Nursikuwagus, "A Mamdani Fuzzy Model to Choose Eligible Student Entry," TELKOMNIKA, vol. 15, no. 1, pp. 365-372, March 2017.

[7] Ajay Kumar, Ajit K. S. Yadav Vinai K. Singh, "Approximations of Fuzzy Systems," Indonesian Journal of Electrical Engineering and Informatics (IJEEI), vol. 1, no. 1, pp. 14-20, March 2013.

[8] Jerry M Mendel, Robert I Jhon, and Feilong Liu, "Interval type-2 fuzzy logic systems made simple," IEEE transactions on fuzzy systems vol.14 no.6, pp. 808-821, 2006.

[9] Humaira, "comparing Type Reduction Algorithm on Type-2 Fuzzy," Matics, vol. 1, no. 1, pp. 1-4, Mar. 2014.

[10] Dongrui Wu, "A brief tutorial on Interval type-2 fuzzy sets and systems," 2011.

[11] M. W. Mustafa, S. N. Khalid M. Mustapha, "Data Selection and Fuzzy-Rules Generation for ShortTerm Load Forecasting Using ANFIS," TELKOMNIKA, vol. 14, no. 3, pp. 791-799, Sept 2016.

[12] Dongrui Wu. (2009, March) Intelligent Systems for Decision Support. Dissertation of University of Southern California.

[13] Efraim Turban, Jay E Aronson, and Ting Peng Liang, Decision Support Systems and Intelligent Systems, 7th ed. New Jersey: Pearson Education, 2005.

[14] Dongrui Wu and Maowen Nie, "Comparison and Practical Implementation of type Reduction Algorithms for Type2 Fuzzy Sets and Systems," 2011.

[15] Matlab R2010b. (2010) Documentation Fuzzy Logic.

[16] Boping Zhang Zhanshen Feng, "Fuzzy Clustering Image Segmentation Based on Particle Swarm Optimization," TELKOMNIKA, vol. 13, no. 1, pp. 128-136, March 2015.

[17] Humaira and R. T. Bambang, "Interval type-2 fuzzy system in supplier selection for new product development," in Proceedings of the 2012 International Conference on System Engineering and Technology, ICSET 2012, 2012. 